\title{
Identification of HLA-A*2402-restricted HCMV immediate early- I (IE-I) epitopes as targets for CD8+ HCMV-specific cytotoxic T lymphocytes
}

\author{
Jong-Baeck Lim¹, Hyun Ok Kim¹, Seok Hoon Jeong ${ }^{1}$, Joo Eun Ha1, \\ Sunphil Jang1, Sang-Guk Lee ${ }^{1}$, Kyungwon Lee ${ }^{1}$ and David Stroncek*2
}

\author{
Address: ${ }^{1}$ Department of Laboratory Medicine, Yonsei University College of Medicine, Seoul, South Korea and ${ }^{2}$ Department of Transfusion \\ Medicine, Warren G. Magnuson Clinical Center, National Institutes of Health, Bethesda, MD, USA \\ Email: Jong-Baeck Lim - jlim@yumc.yonsei.ac.kr; Hyun Ok Kim - hyunok1019@yumc.yonsei.ac.kr; \\ Seok Hoon Jeong - kscpjsh@yumc.yonsei.ac.kr; Joo Eun Ha - 522win@hanmail.net; Sunphil Jang - sunjfeel@yumc.yonsei.ac.kr; Sang- \\ Guk Lee-COMFORTER6@yumc.yonsei.ac.kr; Kyungwon Lee - leekcp@cc.nih.gov; David Stroncek* - dstroncek@cc.nih.gov \\ * Corresponding author
}

Published: 23 August 2009

Journal of Translational Medicine 2009, 7:72 doi:10.1 186/1479-5876-7-72
Received: I June 2009

Accepted: 23 August 2009

This article is available from: http://www.translational-medicine.com/content/7/I/72

(c) 2009 Lim et al; licensee BioMed Central Ltd.

This is an Open Access article distributed under the terms of the Creative Commons Attribution License (http://creativecommons.org/licenses/by/2.0), which permits unrestricted use, distribution, and reproduction in any medium, provided the original work is properly cited.

\begin{abstract}
Background: To identify novel HLA-A*2402-restricted human cytomegalovirus (HCMV) immediate early-I (IE-I) epitopes for adoptive immunotherapy, we explored I 20 overlapping I5amino acid spanning IE-I.

Methods: These peptides were screened by measuring the frequency of polyclonal CD8+ T cells producing intracellular interferon- $\gamma$ (IFN- $\gamma$ ) using flow cytometry and the epitopes were validated with a HCMV-infected target $\mathrm{Cr}$ release cytotoxicity assay.

Results: Initial screening was performed with 12 mini-pools of 10 consecutive peptides made from 120 overlapping peptides 15 -amino acids in length that spanned IE-I. When peripheral blood mononuclear cells (PBMCs) from HLA-A*2402 HCMV-seropositive donors were sensitized with each of the 12 mini-pools, mini-pools I and 2 induced the highest frequency of CD8+ cytotoxic $T$ lymphocytes (CTLs) producing IFN- $\gamma$. When PBMCs were stimulated with each of the twenty peptides belonging to mini-pools $I$ and 2, peptides IE- $I_{1-15}$ MESSAKRKMDPDNPD and IE- $I_{5-}$ ${ }_{19} A K R K M D P D N P D E G P S$ induced the greatest quantities of IFN- $\gamma$ production and cytotoxicity of HLA-matched HCMV-infected fibroblasts. To determine the exact HLA-A*2402-restricted epitopes within the two IE-I proteins, we synthesized a total of twenty-one overlapping 9- or 10 amino acid peptides spanning $\mathrm{IE}-\mathrm{I}_{\mathrm{I}-15}$ and $\mathrm{IE}-\mathrm{I}_{5-19}$. Peptide $\mathrm{IE}-\mathrm{I}_{3-12}$ SSAKRKMDPD induced the greatest quantities of IFN- $\gamma$ production and target cell killing by CD8+ CTLs.
\end{abstract}

Conclusion: HCMV IE- I $_{3-12}$ SSAKRKMDPD is a HLA-A*2402-restricted HCMV IE-I epitope that can serve as a common target for CD8+ HCMV-specific CTLs.

\section{Background}

Human cytomegalovirus (HCMV) infections occurring after allogeneic hematopoietic stem cell transplantation
(HSCT) are frequently associated with high morbidity and mortality despite treatment with appropriate antiviral agents [1-3]. Cytotoxic T lymphocyte (CTL) responses 
have been known to correlate with recovery from HCMV disease in bone marrow transplant (BMT) recipients [4] and CD8+ CTLs are believed to play an important role in suppressing HCMV disease [5-7]. This has led to the development of clinical protocols whereby HCMV-specific $\mathrm{CD} 8+\mathrm{T}$ cell clones are cultured from the transplant donor [8] and are administered to the transplant recipient. The adoptive transfer of these HCMV-specific CD8+ CTLs has proven to be effective in the prevention of reactivation and in the treatment of HCMV infections that are unresponsive to antiviral therapy [9-11].

Although HCMV protein pp65 is known to be an important target for HCMV-specific CTLs and $70 \%$ to $90 \%$ of all HCMV-specific CTLs recognize pp65 epitopes [12-14], CTLs specific for another HCMV protein, immediate early1 (IE-1), occur in infected individuals at frequencies at least comparable to those of pp65-specific CD8+ T cells $[15,16]$. In addition, some recent studies have shown that the dominance and magnitude of the IE- 1 specific CD8+ $\mathrm{T}$ cell response more strongly correlates with protection from HCMV disease than that of CD8+ T cell responses to pp65 [17-19].

Several alternative approaches have been used to generate antigen specific cytotoxic T cells. Antigen presenting cells (APCs) have been genetically modified to which express HCMV pp65 [20,21]. Epstein-Barr virus (EBV)-transformed B lymphoblastic cell lines (EBV-BLCL) have been used to generate EBV-specific CTLs. Genetic manipulation of APCs including dendritic cells (DCs) as well as EBVBLCL result in the natural processing and presentation of HCMV and EBV antigens but their clinical use is complicated by regulatory issues, high cost, and the long duration of time required to qualify viral supernatants and cell therapy products [22].

Several reports have proposed the use of donor-derived HCMV-specific T cells generated by sensitization with HCMV lysates loaded on either donor peripheral blood mononuclear cells (PBMCs) or monocyte-derived cytokine activated dendritic cells $[7,8]$. However, concerns have been raised by regulatory agencies regarding the possibility that lysates of HCMV-infected cells might contain live viral particles that could be transferred to the host and HCMVT cells expanded using viral lysate may be predominantly CD4+ cells [7].

The use of immune-dominant HCMV peptides is another alternative for adoptive immune therapy. Adoptive immune therapy with peptides is feasible as demonstrated by the use of several HCMV-specific peptides derived from pp65 protein to expand large quantities of HCMV-specific CTLs $[9,23]$.
The immune dominance of pp65 and IE-1 proteins among HCMV antigens has been reported, but the number of previously identified CTL epitopes derived from IE-1 protein is limited. The wide clinical application of HCMV-peptide, HLA-restricted, adoptive immune therapy requires the identification of at least one immune dominant HCMV pp65 and IE-1 peptide for each class I HLA antigen. Especially for epitopes such as HLA-A*2402 which is the most frequent HLA-A allele in many different races. To this aim, we report a new HLA-A*2402-restricted pentadecamer peptide from HCMV IE-1, IE- $1_{3-}$ ${ }_{12}$ SSAKRKMDPD, that can be used to stimulate cytotoxic $\mathrm{T}$ cells for adoptive immunotherapy.

\section{Methods}

\section{Donor collection and cell preparation}

Peripheral blood mononuclear cells (PBMCs) were collected from nineteen HLA-A*2402 donors who were HCMV seropositive. The presence of IgG and IgM HCMV antibodies in each donor was analyzed by passive latex agglutination (CMVSCAN kit, Becton-Dickinson Microbiology System, Cockeysville, MD). MHC Class I genotypes were determined by sequence-specific primer PCR using genomic DNA by the HLA laboratory at the Seoul Clinical Laboratory (Seoul, Korea). PBMCs were isolated from the donors' peripheral blood by density-gradient centrifugation using Ficoll-Hypaque 1.077 (Pharmacia Biotech, Wilkstrom, Sweden). The mononuclear cells were washed twice with phosphate buffered saline (PBS, Gibco, Grand Island, NY) and cryopreserved at $-160^{\circ} \mathrm{C}$ in human $\mathrm{AB}+$ serum and basal Iscove's medium (Gibco, Grand Island, NY) containing 10\% DMSO (Sigma, St. Louis, MO). This research was approved by the institutional review board of Yonsei University Health System and all participants gave written informed consent.

\section{Peptide libraries and study design}

Peptide library for HCMV IE-1 protein were made up of 15 -amino acids in length that overlapped by 11 residues and covered the complete IE-1 protein (CMV AD169) [24]. The entire IE-1 library was made up of 120 peptides and these were commercially synthesized (A \& Pep, Yoengi-gun, Korea). The peptides were diluted in DMSO to working solution concentrations and pooled into minipools containing 10 consecutive peptides each. For IE-1, 12 mini-pools of 10 peptides were made. We screened and choose the most immunogenic mini-pools among the 12 mini-pools by quantifying the IFN- $\gamma$ production from the stimulated CD8+ CTLs using flow cytometry as described below. We then screened and identified the best 15 -amino acid peptides among the twenty 15 -amino acid peptides belonging to the selected mini-pools by quantifying the IFN- $\gamma$ production from the stimulated CD8+ CTLs using flow cytometry and HCMV-infected target cell killing assay as described below. For further identification 
of the exact HLA class I restricted-HLA-A*2402 epitopes, we tested a total of twenty-one overlapping nona- or decamer peptides spanning selected 15-amino acid peptides by quantifying the IFN- $\gamma$ production from the stimulated CD8+ CTLs using flow cytometry and HCMVinfected target cell killing assay again. Figure 1 briefly shows the study design.

\section{Generation of autologous dendritic cells (DCs) from PBMCs}

Peptide-loaded autologous DCs were generated as previously described [3,25]. PBMCs obtained after FicollHypaque centrifugation were incubated for 2 hours at $37^{\circ} \mathrm{C}$ in complete RPMI medium. Adherent monocytes were resuspended at a concentration of $5 \times 10^{6} / \mathrm{mL}$ in serum-free medium, supplemented with GM-CSF (1500 IU/mL, Pepro Tech Inc., Rocky Hill, NJ) and IL-4 (1200 IU/mL, Pepro Tech Inc., Rocky Hill, NJ). On days 2, 4, and 6 of culture, fresh cytokines were added. Fresh medium was added depending on cell growth. On day 7 of culture, $10 \mathrm{ng} / \mathrm{mL}$ tumor necrosis necrosis factor- $\alpha$ (TNF- $\alpha, \mathrm{R} \& \mathrm{D}$ Systems, Minneapolis, MN) was added for the maturation of the DCs. After 72-hour maturation, autologous DCs were pulsed with peptides for at least 3 hours.
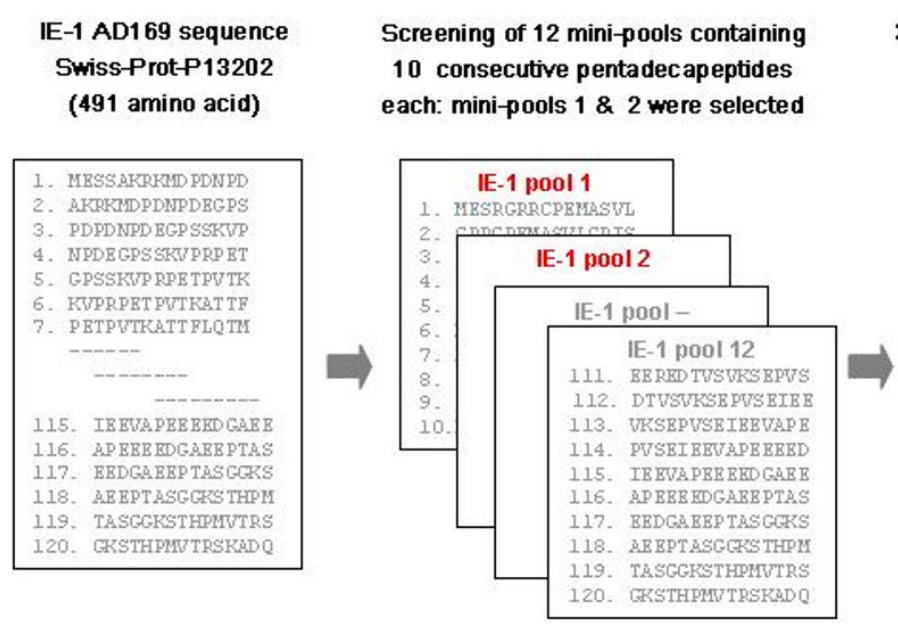

\section{Generation of peptide-specific polyclonal CTLs}

PBMCs from HCMV-seropositive donors were plated at a concentration of $2 \times 10^{6}$ cells per well in a 24 -well culture plate (Nunc, Roskilde, Denmark) with $2 \mathrm{~mL}$ of medium and directly stimulated with peptides at a concentration of $10 \mu \mathrm{g} / \mathrm{mL} /$ well (on day 1) and with peptide-pulsed autologous DCs $\left(4 \sim 10 \times 10^{6} /\right.$ well, on day 7 for a 1 - or 2 week expansion for flow cytometry analysis or cytotoxicity assay, respectively). Recombinant human interleukin-2 (rhIL-2, 100 IU/mL, Pepro Tech Inc., Rocky Hill, NJ) was added to the culture every other day and the cells were cultured for 14 days.

\section{Detection of IFN- $\gamma$ producing CD8+ T cells in response to peptide stimulation by flow cytometry}

Two- week peptide-expanded PBMCs $\left(1 \times 10^{6}\right)$ stimulated with PHA (Sigma, St. Louis, MO) and PBMCs stimulated with autologous DCs that were not loaded with any peptide were used as positive and negative controls respectively. HCMV pp65 ${ }_{495-503}$ (NLVPMVATV, HLA-A*0201) or pp65 $341-350$ (QYDPVAALFF, HLA-A*2402), pp65 $91-100$ (SVNVHNPTGR, HLA-A33) were used as positive or negative controls according to donor's HLA type [3,24]. One hour after stimulation, $10 \mathrm{mg}$ of Brefeldin A (Sigma, St. Louis, MO) was added to each well. After 5 additional
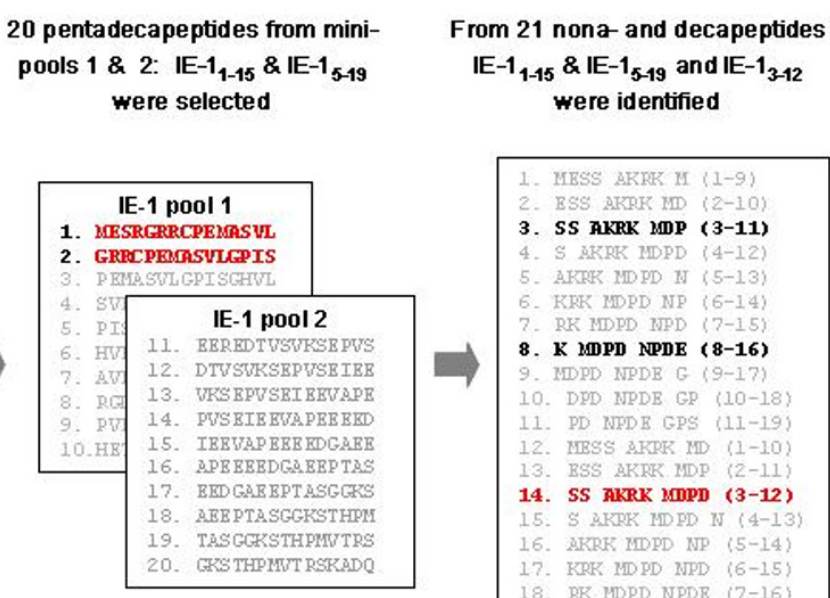

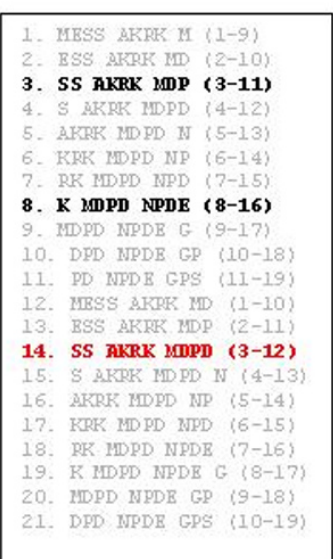

\section{Figure I}

IE-I peptide library and study design. The library of peptides spanning HCMV IE-I was made up of I 20 peptides I5 amino acids in length that overlapped by II residues which were used to make 12 mini-pools each containing 10 consecutive peptides. We screened and choose the most immunogenic mini-pools by quantifying IFN- $\gamma$ production by stimulated CD8+ CTLs using intracellular flow cytometry analysis. After finding that mini-pools I and 2 were the most potent stimulators of IFN- $\gamma$, we screened and choose the best I5-amino acid peptides among twenty I5-amino acid peptides belonging to these two mini-pools by quantifying IFN- $\gamma$ production by peptide stimulated CD8+ CTLs using flow cytometry and a HCMV-infected target cell killing assay. Next, we identified the exact HLA class I restricted-HLA-A*2402 epitope by screening a total of twenty-one overlapping nona- or decamer peptides spanning selected 15 -amino acid peptides. These 21 peptides were also tested by intracellular flow cytometry and cytotoxicity assays. 
hours of incubation, PBMCs were washed once with PBS and were then incubated in PBS containing $1 \mathrm{mM}$ EDTA for 10 minutes. After two further washes with PBS and 5\% fetal calf serum (FCS, Biosource International, Rockville, $\mathrm{MD}$ ) the cells were incubated with fluorescence-labeled monoclonal antibodies for 15 minutes on ice in the dark. Staining and analysis was performed as previously described $[3,14,26]$.

\section{Antibodies and flow cytometry analysis}

FITC-conjugated anti-IFN- $\gamma$, PerCP-conjugated antiCD69, PerCP-conjugated anti-CD3 and PE-conjugated anti-CD8 were purchased from BD Biosciences. Per sample, 50,000-100,000 events in the FSC/SSC lymphocyte gate were acquired on a FACS Calibur flow cytometer (Becton Dickinson, San Jose, CA). For data analysis (CELLQuest software; Becton Dickinson), CD3+/CD8+ events were displayed in a CD69+ versus IFN- $\gamma$ dot plot. CD8+/ IFN- $\gamma$ cells were expressed as a percent of the respective reference population. The assessment of responses was previously described in more detail $[3,14,26]$.

\section{Fibroblast cell lines as target cells}

Fibroblasts from allogeneic donor (HLA-A*2402) derived skin biopsies were used as target cells. The fibroblasts were propagated in MEM- $\alpha$ supplemented with 1\% NEAA (nonessential amino acid, Sigma, St. Louis, MO), 10\% fetal calf serum, and antibiotics. AD-169 HCMV strain (VR-538, American Type Culture Collection, Manassas, VA) was propagated in fibroblasts and the infected cultures were harvested when a cytopathic effect was evident. The cells were spun at $1500 \mathrm{rpm}$ for 10 minutes and aliquots of supernatant were stored at $-80^{\circ} \mathrm{C}$ until use. HCMV infectivity of the fibroblasts was confirmed by HCMV-specific real time RT-PCR testing that targeted the HCMV IE1 antigen (Roche, Nutley, NJ)

\section{Cytotoxicity assays}

Cytotoxicity assays were performed employing ${ }^{51} \mathrm{Cr}$ release as previously described $[27,28]$. Briefly, HCMVinfected fibroblasts were labeled overnight with ${ }^{51} \mathrm{Cr}(100$ $\mathrm{mCi} / 10^{6}$ cells; PerkinElmer Life and Analytical Science, Waltharn, MA), washed in PBS, and dispensed in triplicate into 96-well V-bottom plates (Nunc, Roskilde, Denmark) at $4 \times 10^{3}$ cells/well. CTLs were added to the infected fibroblasts at an effector to target cell ratio of 10:1, 30:1, 50:1 and 100:1. The cells were pelleted and after a 5 hour incubation period the supernatant was analyzed in a gamma counter. Spontaneous and total release counts for each well were used to calculate percent specific release with the following formula: $\%$ specific release $=$ (experimental cpm - spontaneous cpm)/(total cpm spontaneous cpm).

\section{Results \\ Screening IE-I peptide mini-pools by induction of IFN- $\gamma$ production by CD8+T cells}

To determine which of the 12 mini-pools contained potential immune dominant candidate peptides, PBMCs from five HLA-A*2402 HCMV-seropositive donors (donor 1-5) were stimulated with each of the 12 minipools. Intracellular IFN- $\gamma$ production was measured by flow cytometry. As a positive control, PBMCs from HCMV-seropositive donors were stimulated with both phytohemaglutinin (PHA) and pp65 $328-335$ (QYDPVAALF, HLA-A*2402) [24]. In addition, PBMCs from donors incubated without any peptide or with pp65 $5_{91-100}$ (SVNVHNPTGR, HLA-A33) [3] were used as negative controls. Among the 12 mini-pools, mini-pool 1 induced a greater frequency of IFN- $\gamma$ producing $\mathrm{CD} 8+$ cytotoxic $\mathrm{T}$ cells than mini-pools 3 through 12 in four of the five donors. In addition, mini-pool 2 induced a higher frequency of IFN- $\gamma$ producing CD8+ cytotoxic T cells than mini-pools 3 through 12 in three of the five donors. Therefore, both peptide mini-pools 1 and 2 were selected for further study. A representative experiment is illustrated in Figure 2.

\section{Identification of specific I5-amino acid candidate eptitopes by in vitro sensitization and induction of IFN- $\gamma$ production}

To determine which 15 -amino acid peptides belonging to mini-pools 1 and 2 had the capacity to specifically reinduce CTL immune activity, intracellular IFN- $\gamma$ production of CD $8+\mathrm{T}$ cells was measured in HCMV-seropositive HLA-A* 2402 cells from five donors (Donors 2, 3, and 68 ) that had been in vitro sensitized for a week with each of the twenty candidate 15-amino acid peptides. After a one week in vitro sensitization PBMCs were restimulated with dendritic cells derived from autologous monocytes which were loaded with each of the twenty 15 -amino acid peptides. After a 6-hour resensitization, intracellular IFN- $\gamma$ protein production by CD8+ T cells from the HCMVseropositve HLA-A*2402 donors was measured by intracellular flow cytometry. In a representative experiment illustrated in Figure 3, in all donors peptides IE- $1_{1-}$ ${ }_{15}$ MESSAKRKMDPDNPD and IE- $1_{5-19}$ AKRKMDP DNPDEGPS consistently induced greater quantities of IFN- $\gamma$ production than the other 15-amino acid peptides tested. As a control, the PBMCs were also sensitized in vitro for a week with the HLA-A*2402-restricted epitope, pp65 328 ${ }_{335}$ QYDPVAALF and the HLA-A*0201-restricted epitope, pp65 $495-503$ NLVPMVATV [14] as positive controls and with the HLA-A*3303-restricted epitope, pp $65_{91-100}$ SVNVHNPTGR, as a negative control.

These results suggest that IE- $1_{1-15}$ MESSAKRKMDPDNPD and IE- $1_{5-19}$ AKRKMDPDNPDEGPS are potential HLA- 


\section{Donor 2 (A0201/2402)}

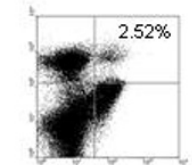

IL-2

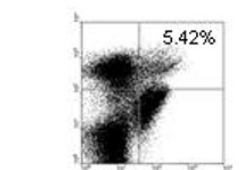

Mini-pool 1

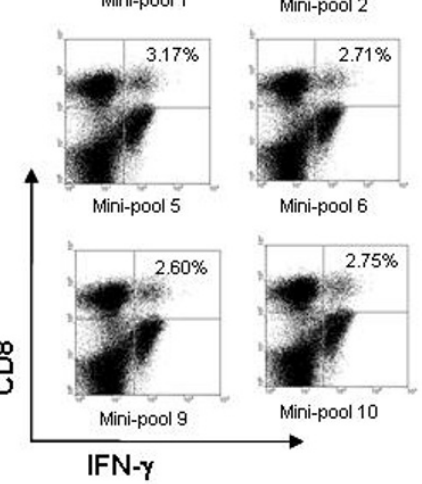

Figure 2

Results of screening of the I 2 peptide mini-pools by quantifying intracellular IFN- $\gamma$ by $\mathrm{CD8}+\mathrm{T}$ cells. To select the most potential immune-dominant epitopes PBMCs from five HLA-A*2402 HCMV-seropositive donors (Donors I-5) were stimulated with each of the 12 mini-pools and intracellular IFN- $\gamma$ production was measured by flow cytometry. The results of testing cells from Donor 2 who expressed HLA-A*020I/2402 are shown. Peptide mini-pools I and 2 showed a higher frequency of IFN- $\gamma$ accumulation by CD8+ $\mathrm{T}$ cells than the other mini-pools. Therefore, mini-pools I and 2 were selected for further study. PHA and HCMV A2 (Pp65 495-503) peptide-stimulated PBMCs were used as positive controls and HCMV A33 (pp6591-100) peptide and IL-2 only stimulated PBMCs (IL-2) were used as negative controls.

A*2402-restricted HCMV IE-1 epitopes and both peptides were selected for further study.

\section{Analysis of the peptide-specific cytotoxicity of the two 15 amino acid peptides}

To confirm that IE- $1_{1-15}$ MESSAKRKMDPDNPD and IE$1_{1_{-1} 9}$ AKRKMDPDNPDEGPS are immune dominated peptides for HLA-A*2402 subjects, PBMCs from three HLAA*2402 HCMV-seropositive donors (Donors 9, 10 and 11) were sensitized in vitro for two weeks with the candidate pentadecapeptides. The in vitro sensitized cells were tested for cytotoxicity against HLA-matched HCMVinfected targets. The cytotoxicity assay was carried out by measuring ${ }^{51} \mathrm{Cr}$ release from HLA-A*2402 HCMVinfected fibroblasts. For all three donors tested IE- $1_{1-15}$
MESSAKRKMDPDNPD- and IE- (5-19 $_{\text {AKRKMDP DNP- }}$ DEGPS-sensitized CTLs lysed greater quantities of HCMVinfected fibroblasts than the negative control cells. PBMCs from donors 9 and 10 that were in vitro sensitized for 2 weeks with IE- $1_{1-15}$ MESSAKRKMDPDNPD were highly cytotoxic to HLA-A*2402 HCMV-infected fibroblasts. PBMCs in vitro sensitized with IE- $1_{1-}$ ${ }_{15}$ MESSAKRKMDPDNPD lyzed a similar proportion of HCMV-infected fibroblasts as PBMCs sensitized with pp65 $495-503$ which was used as a positive control (Figure $4 \mathrm{~A}, \mathrm{~B})$. However, in donor 11 IE- $1_{5-19}$ AKRKMDPDNP DEGPS showed higher cytotoxicity to HLA-A*2402 HCMV-infected fibroblasts than that of IE- $1_{1-}$ ${ }_{15}$ MESSAKRKMDPDNPD (Figure 4C). These results confirmed that both of IE- $1_{1-15}$ MESSAKRKMDPDNPD and IE- $1_{5-19}$ AKRKMDPDNPDEGPS were likely to be the best immunogenic epitopes for HLA-A*2402 among HCMV IE-1 proteins. Next, we identified the most immunogenic nona- or decarmer MHC class I-restricted peptides spanning IE- $1_{1-15}$ and IE- $1_{5-19}$ using a HCMV-infected fibroblast cytotoxicity assay.

\section{Ex vivo sensitization with 9- and 10 amino acid peptides spanning IE-II-15 and IE- $15-19$}

To determine the exact HLA class I restricted HCMV IE-1 protein epitopes that were immunogenic in HLA-A*2402 subjects, we synthesized and tested a total of twenty-one overlapping nona- or decamer peptides spanning IE- $1_{1-15}$ and IE- $1_{5-19}$. Intracellular IFN- $\gamma$ protein production was measured in cells from seven HCMV-seropositive HLAA*2402 donors (Donors 12-18) that had been in vitro sensitized for 2 weeks with each of the twenty-one candidate peptides. Among the twenty-one candidate peptides, IE- $1_{3-11}$ SSAKRKMDP, IE-1 $1_{3-12}$ SSAKRKMDPD and IE- $1_{8-}$ ${ }_{16} \mathrm{KMDPDNPDE}$ induced greater quantities of IFN- $\gamma$ production than the other peptides tested. Peptide IE- $1_{3-}$ ${ }_{12}$ SSAKRKMDPD was especially potent. It induced greater quantities of IFN- $\gamma$ production than the other two peptides in six of seven donors. Therefore, IE- $1_{3-}$ ${ }_{12}$ SSAKRKMDPD was likely the most immunogenic HLAA*2402 epitope within HCMV IE-1. A representative experiment using cells from donor 14 is illustrated in Figures $5 \mathrm{~A}$ and $5 \mathrm{~B}$. The response of donor 14 's CD8+ cells to IE- $1_{8-16}$ KMDPDNPDE was weak (Figure $5 \mathrm{~A}$ ), but IE- $1_{8-}$ ${ }_{16} \mathrm{KMDPDNPDE}$ stimulated significant quantities of IFN$\gamma$ in CD8+ cells from five of the seven HLA-A*2402 expressing donors tested.

\section{HCMV IE-13-12 SSAKRKMDPD specific cytotoxicity}

To provide further evidence that IE- $1_{3-12}$ SSAKRKMDPD induced epitope-specific and HLA-A*2402-restricted cytotoxicity, PBMCs from a donor expressing HLA-A*2402 (Donor 19) were sensitized in vitro for 2 weeks with IE-1 ${ }_{3-}$ ${ }_{11}$ SSAKRKMDP, IE-1 ${ }_{3-12}$ SSAKRKMDPD and IE- $1_{8-}$ ${ }_{16}$ KMDPDNPDE. The in vitro sensitized cells were tested 
Donor $2($ HLA-A*0201/2402)

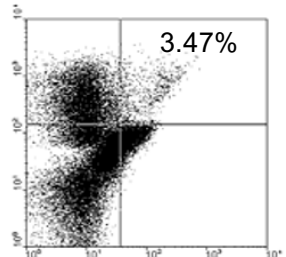

IL-2

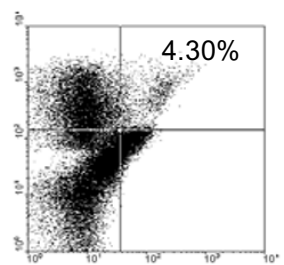

IE-1 $1_{1-15}$

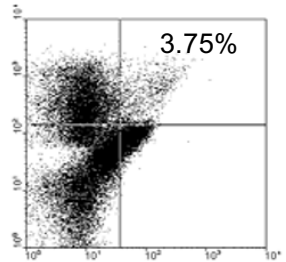

IE-1 ${ }_{21-35}$

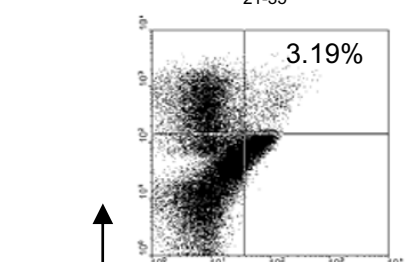

IE-1 ${ }_{41-55}$

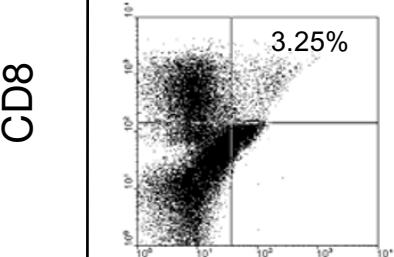

$\mathrm{IE}-1_{61-75}$

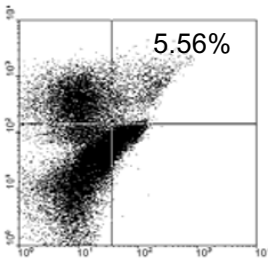

PHA

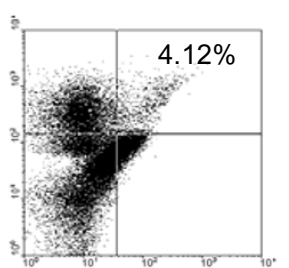

IE-1 ${ }_{5-19}$

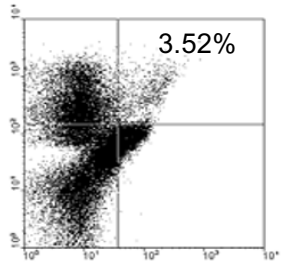

IE-1 ${ }_{25-39}$

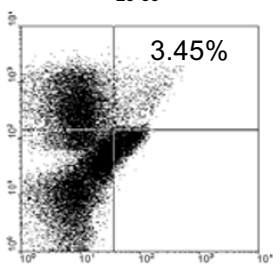

IE-1 ${ }_{45-59}$

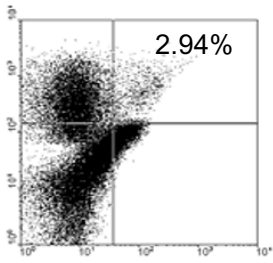

IE-1 ${ }_{65-79}$

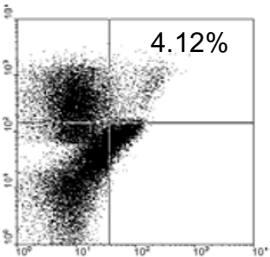

CMV A02

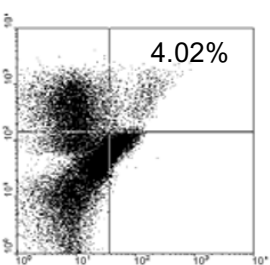

IE-19-23

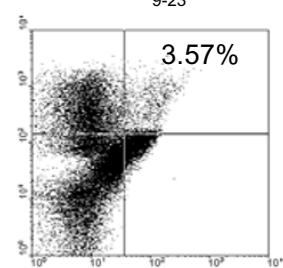

IE- $1_{29-43}$

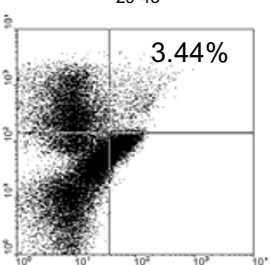

IE-1 $199-63$

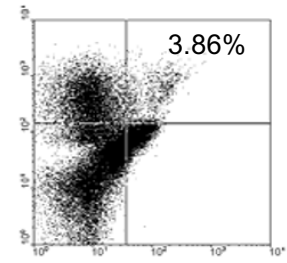

IE-1 ${ }_{69-83}$

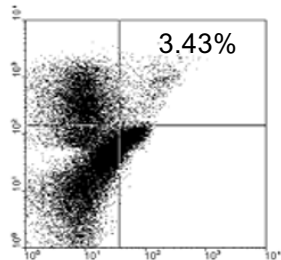

CIMV A33

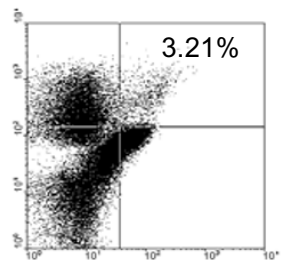

IE-1 ${ }_{13-27}$

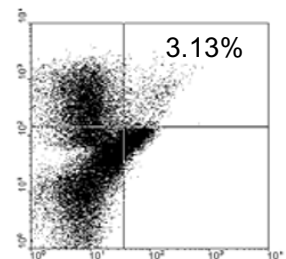

IE-1 $1_{33-47}$

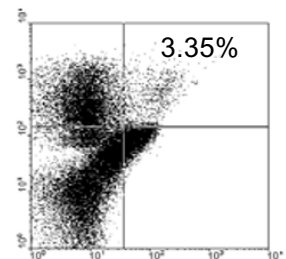

IE-1 $1_{53-67}$

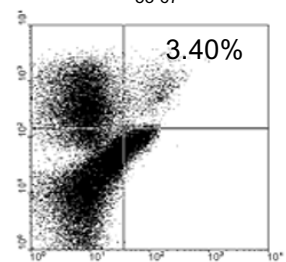

IE-1 ${ }_{73-87}$

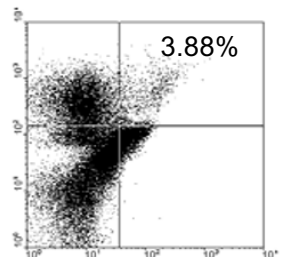

IE-1 ${ }_{17-31}$

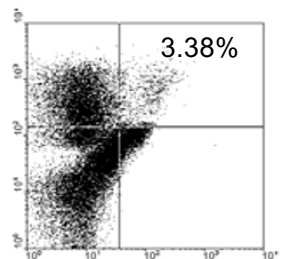

IE-1 ${ }_{37-51}$

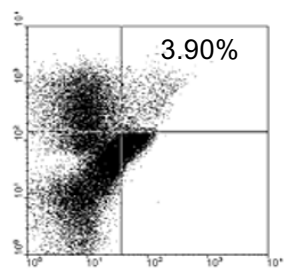

IE-1 $1_{57-71}$

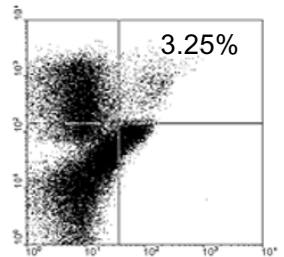

IE-1

IFN- $\gamma$

\section{Figure 3}

Intracellular IFN- $\gamma$ protein production by HLA-A 2402 CD8+ CTLs stimulated with the twenty individual I5amino acid peptides included in mini-pools $I$ and 2. To determine which $I 5$-amino acid peptides belonging to mini-pools I and 2 had the capacity to specifically re-induce CTL immune activity, intracellular IFN- $\gamma$ production by CD8+ T cells was measured in HCMV-seropositive HLA-A*2402 cells from five donors (Donors 2, 3, and 6-8) that had been in vitro sensitized for a week with each of the twenty candidate 15 -amino acid peptides. The results of testing cells from Donor 2 are shown. Peptides IE- $I_{\mid-15}$ MESSAKRKMDPDNPD and IE- $I_{5-19}$ AKRKMDPDNPDEGPS consistently induced greater quantities of IFN- $\gamma$ protein production than the other 15 -amino acid peptides tested. PHA and HCMV A2 (Pp65 495-503 $_{\text {) }}$ peptide-stimulated PBMCs were used as positive control and HCMV A33 (Pp65 $99_{1-100}$ ) peptide and IL-2 only stimulated PBMCs (IL-2) were used as negative controls. 
for cytotoxicity using a ${ }^{51} \mathrm{Cr}$ release assay against HLAmatched HCMV-infected targets. IE- $1_{3-12}$ SSAKRKMDPDsensitized CTLs lysed greater quantities of HCMV-infected fibroblasts than the negative control cells. CTLs sensitized with IE- $1_{5-16}$ KMDPDNPDE also lysed greater quantities of HCMV-infected fibroblasts than the negative control cells, but they lysed less HCMV-infected fibroblasts than CTLs sensitized with IE-1 ${ }_{3-12}$ SSAKRKMDPD (Figure 6).

\section{Discussion}

This study focused on the identification of novel HLAA*2402 CTL epitopes derived from HCMV IE-1 protein using pools of overlapping 15-amino acid peptides. These HCMV-specific HLA-restricted epitopes will be useful for vaccination, adoptive immunotherapy, and the monitoring of cellular immune response against HCMV disease in transplant recipients.

Over the last decade vaccination strategies using the immunogenic peptides derived from several HCMV proteins have been successful in preventing the reactivation of latent HCMV infection [17-19]. One of the most important steps in a peptide vaccine approach is the identification of immunogenic epitopes within HCMV proteins, which bind to HLA Class I molecules that are expressed by a major proportion of the population
[29,30]. Although HLA-A24 is the most frequent HLA-A antigen among Asians, HLA-A24-restricted HCMV IE-1 epitopes have not yet been described.

Many current strategies for selecting potentially immunogenic epitopes are based on the use of algorithms that predict the binding affinities of specific peptides to HLA Class I molecules. Peptides predicted to have a high binding affinity are tested for their ability to sensitize CTLs. This strategy can be a very effective way of identifying new immune dominant peptides, but it has been useful for only a limited number of peptide sequences and HLA alleles $[31,32]$. Furthermore, as demonstrated by Elkington et al, even for those HCMV-pp65 peptides that were predicted to bind to common HLA alleles, only $40 \%$ elicited cytokine-producing $\mathrm{T}$ cells detected by enzyme linked immunospot (ELISPOT) assays, and only a subset of the T-cell lines generated from HLA-A*0201-seropositive donors in response to these peptides actually lysed HCMV-infected cells [33]. We have explored another method to identify HLA-A24-restricted HCMV IE-1 epitopes. Pools of overlapping 15-amino acid peptides spanning the sequence of HCMV IE-1 were used for sensitization and generation of HCMV-specific T cells. Such 15amino acid peptides previously have been used to identify immunogenic viral epitopes recognized by $\mathrm{T}$ cells in the
A

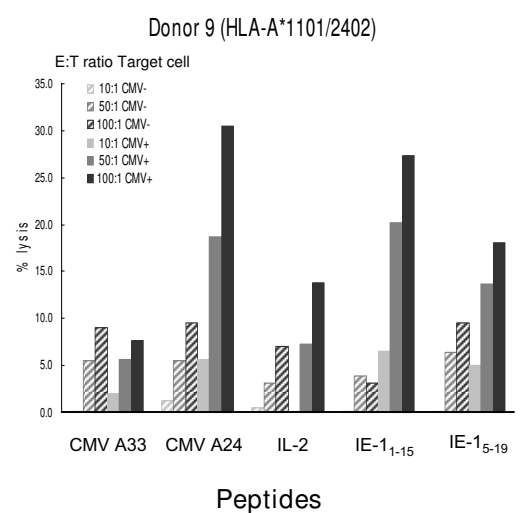

B

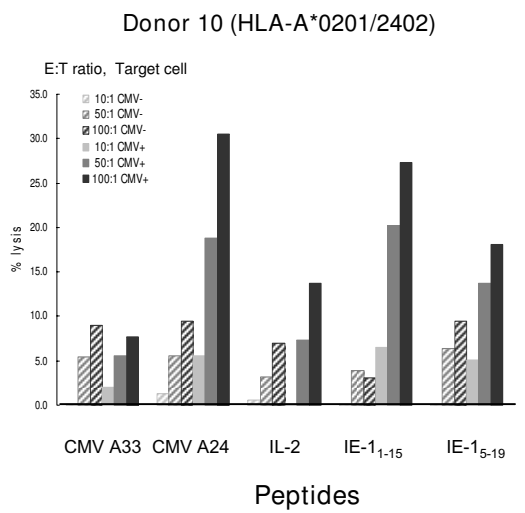

C

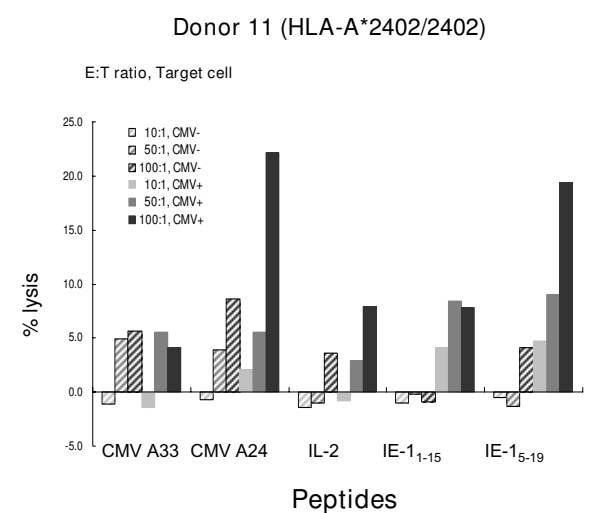

\section{Figure 4}

Cytotoxic effects of IE-I $I_{I-15}$ and IE- $I_{5-19}$ peptide-specific CTLs against CMV-infected fibroblast. PBMCs from three HLA-A*2402 HCMV-seropositive donors (Donors 9,I0 and I I) were sensitized in vitro for two weeks with IE-I I${ }_{15}$ MESSAKRKMDPDNPD and IE- $I_{5-19}$ AKRKMDPDNPDEGPS and the in vitro sensitized cells were tested for cytotoxicity against HLA-matched HCMV-infected fibroblast. The cytotoxicity assay was carried out by measuring ${ }^{5 I} \mathrm{Cr}$ release from HLAA*2402 HCMV-infected fibroblasts. PBMCs from Donor 9 (Figure 4A) and Donor 10 (Figure 4B) that were in vitro sensitized

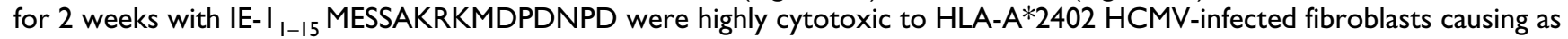
much targeted cell lysis as PBMCs sensitized with a positive control. However, in Donor II, IE-I ${ }_{5-19}$ AKRKMDPDNPDEGPS showed higher cytotoxicity to HCMV-infected fibroblasts than that of IE-I I-I5 MESSAKRKMDPDNPD (Figure 4C). PMBCs stimulated with the HLA-A24-restricted HCMV pp65 epitope HCMV A24 (Pp65 34 I-350) was used as positive control and PBMCs stimulated with the HCMV-A33 restricted epitope CMV A33 (pp65,-100) peptide and PBMCs simulated only with IL-2 (IL-2) were used as negative controls. 
blood of healthy individuals and allograft recipients [25]. By analysis of responses to intersecting mini-pools, specific 15-amino acid peptides containing immunogenic epitopes were identified and the epitopes subsequently defined by testing responses to individual 9 or 10 amino acid sequences contained in these 15 -amino acid peptides [26].

In our study a total of twelve mini-pools contained 10 consecutive 15-amino acid peptides were prepared using one hundred-twenty 15-amino acid peptides spanning HCMV IE-1 protein. The peptide pools were screened by quantifying the production of IFN- $\gamma$ by CD8+ T cells from four HLA-A*2402 donors using flow cytotometry analysis. Mini-pool 1 (Donors 1, 2, 3, and 4) and mini-pool 2 (Donors 1 and 2) induced higher frequencies of CD8+ T cells producing IFN- $\gamma$ than the other mini-pools. Mini- pools 5,7 and 9 showed a higher frequency IFN- $\gamma$ production in a single donor (Donor 2, Donor 3 and Donor 1, respectively) (data not shown). Therefore, mini-pools 1 and 2 were selected for further characterization and all twenty 15-amino acid peptides belonging to these mini-pools were screened using flow cytometry analysis. Among twenty 15-amino acid peptides, IE- $1_{1-}$ ${ }_{15}$ MESSAKRKMDPDNPD and IE- $1_{5-19}$ AKRKMDPDNP DEGPS induced the highest frequency of IFN- $\gamma$ producing CD8+ T cells and PBMCs sensitized with these two 15amino acid peptides showed in vitro cytotoxicity against HCMV-infected fibroblast.

Virus-infected human cells can be recognized by CD8+ T cells through antigenic viral protein fragments of 8-12 amino acids in length that are presented on the cell surface in association with HLA class I molecules. Since these
A Donor $14\left(H L A-A^{*} 2402 / 3303\right)$

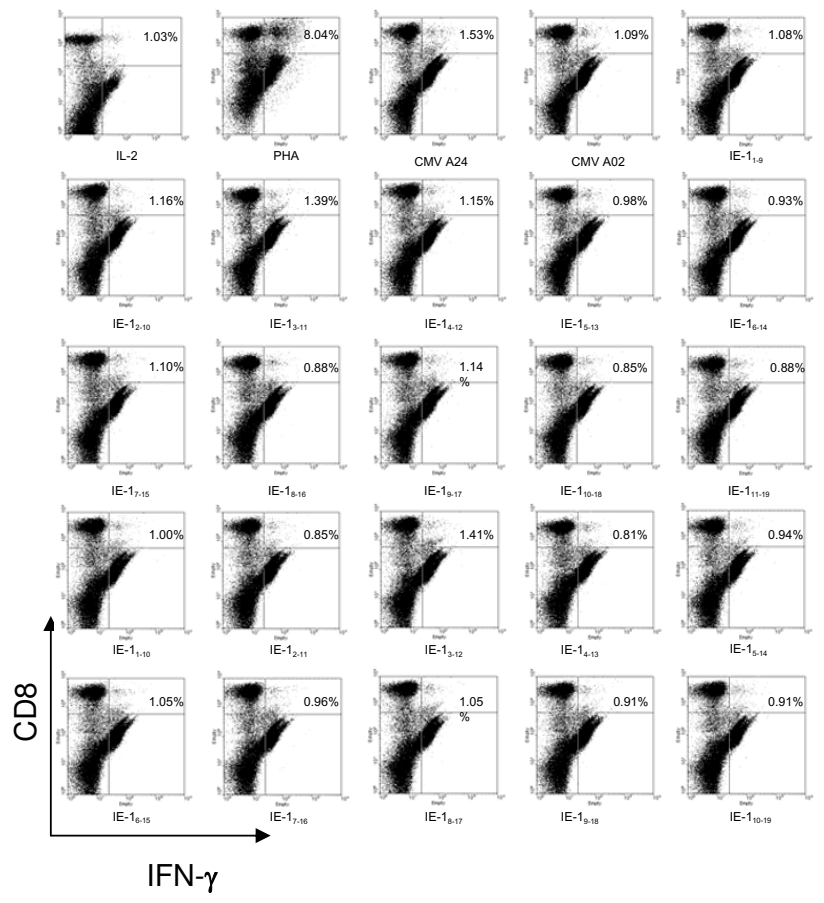

B

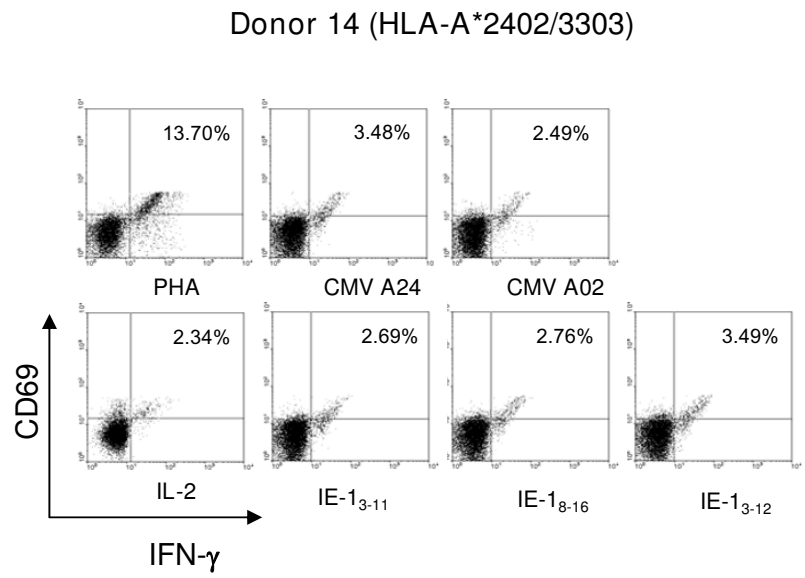

Figure 5

Intracellular IFN- $\gamma$ analysis of IE- $I_{|-| 5}$ and IE- I $_{5-19}$ derived HCMV-specific CTLs. To determine the exact HLA class I restricted- HLA-A*2402 specific IE-I epitopes, we synthesized a total of twenty-one overlapping nona- or decamer peptides spanning IE-I $I_{I-15}$ and IE-I ${ }_{5-19}$. Intracellular IFN- $\gamma$ protein production was measured in six HCMV-seropositive HLA-A*2402 donors (Donors I2-I7). Among the twenty-one candidate peptides, IE-I I $_{3-11}$ SSAKRKMDP, IE-I ${ }_{3-12}$ SSAKRKMDPD and IE-I $_{8-}$ ${ }_{16}$ KMDPDNPDE peptide induced the highest quantities of IFN- $\gamma$ protein production. Peptide IE- I $_{3-12}$ SSAKRKMDPD induced the greatest quantities of IFN- $\gamma$ production in five of six donors. The results of testing Donor I4 are shown. The peptide IE- I ${ }_{12}$ SSAKRKMDPD induced higher quantities of IFN- $\gamma$ production by CD8+ CTLs from Donor I 4 than any of the other peptides tested (Panel A). In addition, this peptide also induced the greatest quantities of IFN- $\gamma$ protein production by CD8+CD69+ CTLs (Panel B). PHA and CMV A24 (Pp65 $34 \mid-350$ ) peptide-stimulated PBMCs were used as positive control and CMV A2 (Pp65 $495-503$ ) peptide and IL-2 only stimulated PBMCs (IL-2) were used as negative controls. 


\section{Donor 19 (HLA-A*0203/2402)}

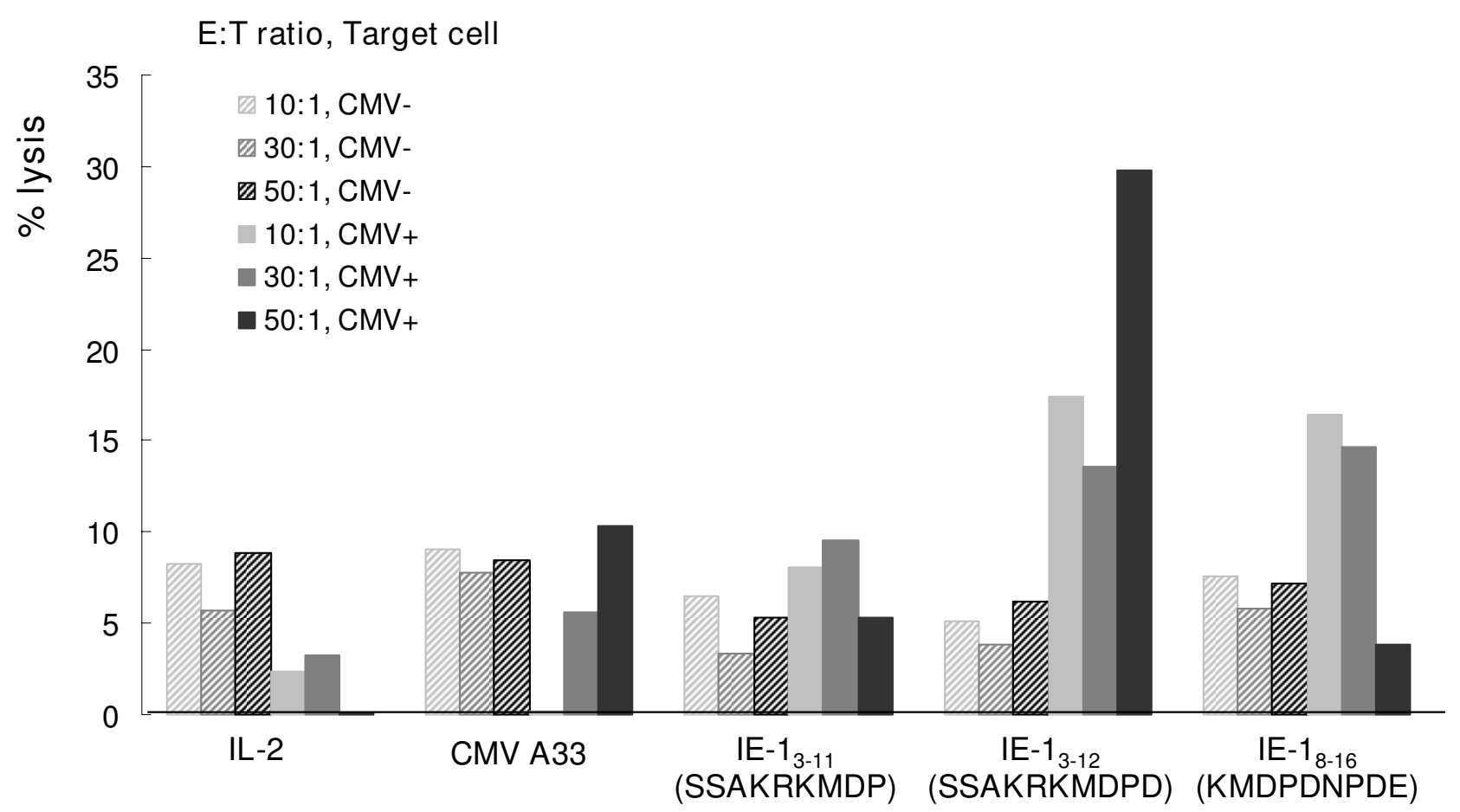

Figure 6

HCMV IE-I 3-12 $_{2}$ SSAKRKMDPD specific cytotoxicity. PBMCs from donors expressing HLA-A*2402 (Donor I9) were sensitized in vitro for 2 weeks with IE- $I_{3-11}$ SSAKRKMDP, IE- $I_{3-12}$ SSAKRKMDPD and IE- $I_{8-16}$ KMDPDNPDE and tested for cytotoxicity using a ${ }^{51} \mathrm{Cr}$ release assay against HLA-matched HCMV infected fibroblasts. The IE-I $3-12$ SSAKRKMDPD sensitized CTLs lysed greater quantities of HCMV-infected fibroblasts than the negative controls. HCMV A33 (PP65 34 I-350) peptide and IL-2 only stimulated PBMCs (IL-2) were used as negative controls.

smaller peptides can be generated by extracellular processing [25], eleven 9 -amino acid peptides with 8 overlapping amino acids and ten 10 -amino acid peptides with 9 overlapping amino acids spanning IE- $1_{1-15}$ MESSAKRKMDPDNPD and IE- $1_{5-19}$ AKRKMDPDNPDEGPS were synthesized and tested further for identification of HLAA*2402-restricted HCMV IE-1 epitopes. Among the 21 overlapping peptides, IE- $1_{3-11}$ SSAKRKMDP, IE- $1_{3-12}$ SSAKRKMDPD and IE- $1_{8-16}$ KMDPDNPDE induced the greatest frequencies of IFN- $\gamma$ producing CD $8+$ T cells. Peptide IE- $1_{3-12}$ SSAKRKMDPD induced the highest frequency of IFN- $\gamma$ producing CD $8+$ T cells. Although when analyzed by a computer algorithm each of these three peptides scored a low rank estimated half-time of dissociation from the HLA-A24 allele, all three peptides induced high frequencies of polycolonal CD8+ T cells producing IFN- $\gamma$; were presented successfully by the HLA-A*2402 allele of HCMV-infected fibroblast cell lines; and induced strong cytotoxicity against HCMV-infected fibroblasts. This sug- gests that these three peptides are processed naturally and presented successfully in vitro.

In conclusion, we have identified a possible HLA-A*2402 CTL epitope, IE- $1_{3-12}$ SSAKRKMDPD, derived from HCMV IE-1 protein using overlapping peptides 15-amino acids in length. This peptide was processed naturally in HCMV-infected human fibroblast and presented successfully on the HLA-A*2402 allele and was well recognized by HCMV-specific polyclonal CD8+ cytotoxic T cells.

\section{Conclusion}

HCMV IE- $1_{3-12}$ SSAKRKMDPD is a possible HCMV-specific epitope for vaccination, adoptive immunotherapy, and the monitoring of cellular immune response against HCMV disease in transplant recipients.

\section{Conflict of interests}

The authors declare that they have no competing interests. 


\section{Authors' contributions}

JBL designed the research, preformed research, analyzed data, and wrote the paper. HOK designed the research, was responsible for the collection of PBMCs and histocompatibility testing, analyzed data, and wrote the paper. $\mathrm{SHJ}$ designed the research, performed research, analyzed data and wrote the paper. JEH performed research, analyzed data, and wrote the paper. SJ performed research, analyzed data and wrote the paper. SGL performed research, analyzed data and wrote the paper. KL designed the research and editing the paper. DFS designed the research and wrote the paper.

\section{Acknowledgements}

This work was supported by KOSEF through the National Core Research Center for Nanomedical Technology (RI5-2004024-0I00I-0).

\section{References}

I. Einsele H, Hebart H, Kauffmann-Schneider C, Sinzger C, Jahn G, Bader P, Klingebiel T, Dietz K, Loffler J, Bokemeyer C, Muller CA, Kanz $L$ : Risk factors for treatment failures in patients receiving PCR-based preemptive therapy for CMV infection. Bone Marrow Transplant 2000, 25:757-763.

2. Szmania S, Galloway A, Bruorton M, Musk P, Aubert G, Arthur A, Pyle H, Hensel N, Ta N, Lamb L Jr, Dodi T, Madrigal A, Barrett J, HensleeDowney J, van Rhee F: Isolation and expansion of cytomegalovirus-specific cytotoxic $T$ lymphocytes to clinical scale from a single blood draw using dendritic cells and HLA-tetramers. Blood 200I, 98:505-5I 2.

3. Lim JB, Provenzano M, Kwon OH, Bettinotti M, Caruccio L, Nagorsen D, Stroncek D: Identification of HLA-A33-restricted CMV pp65 epitopes as common targets for CD8(+) CMV-specific cytotoxic T lymphocytes. Exp Hematol 2006, 34:296-307.

4. Quinnan GV Jr, Kirmani N, Rook AH, Manischewitz JF, Jackson L, Moreschi G, Santos GW, Saral R, Burns WH: Cytotoxic t cells in cytomegalovirus infection: HLA-restricted T-lymphocyte and non-T-lymphocyte cytotoxic responses correlate with recovery from cytomegalovirus infection in bone-marrowtransplant recipients. N Engl J Med 1982, 307:7-13.

5. Riddell SR, Watanabe KS, Goodrich JM, Li CR, Agha ME, Greenberg PD: Restoration of viral immunity in immunodeficient humans by the adoptive transfer of T cell clones. Science 1992, 257:238-24l.

6. Walter EA, Greenberg PD, Gilbert MJ, Finch RJ, Watanabe KS, Thomas ED, Riddell SR: Reconstitution of cellular immunity against cytomegalovirus in recipients of allogeneic bone marrow by transfer of T-cell clones from the donor. N Engl J Med 1995, 333: 1038-1044.

7. Einsele H, Roosnek E, Rufer N, Sinzger C, Riegler S, Loffler J, Grigoleit U, Moris A, Rammensee HG, Kanz L, Kleihauer A, Frank F, Jahn G, Hebart H: Infusion of cytomegalovirus (CMV)-specific T cells for the treatment of CMV infection not responding to antiviral chemotherapy. Blood 2002, 99:3916-3922.

8. Peggs K, Verfuerth S, Mackinnon S: Induction of cytomegalovirus (CMV)-specific T-cell responses using dendritic cells pulsed with CMV antigen: a novel culture system free of live CMV virions. Blood 200I, 97:994-1000.

9. Carlsson B, Cheng WS, Totterman TH, Essand M: Ex vivo stimulation of cytomegalovirus (CMV)-specific T cells using CMV pp65-modified dendritic cells as stimulators. $\mathrm{Br} J$ Haematol 2003, I $21: 428-438$.

10. Peggs KS, Mackinnon S: Augmentation of virus-specific immunity after hematopoietic stem cell transplantation by adoptive T-cell therapy. Hum Immunol 2004, 65:550-557.

II. Cobbold M, Khan N, Pourgheysari B, Tauro S, McDonald D, Osman $\mathrm{H}$, Assenmacher M, Billingham L, Steward C, Crawley C, Olavarria E, Goldman J, Chakraverty R, Mahendra P, Craddock C, Moss PA: Adoptive transfer of cytomegalovirus-specific CTL to stem cell transplant patients after selection by HLA-peptide tetramers. J Exp Med 2005, 202:379-386.
12. Li CR, Greenberg PD, Gilbert MJ, Goodrich JM, Riddell SR: Recovery of HLA-restricted cytomegalovirus (CMV)-specific T-cell responses after allogeneic bone marrow transplant: correlation with CMV disease and effect of ganciclovir prophylaxis. Blood 1994, 83: 197I-1979.

13. Wills MR, Carmichael AJ, Mynard K, Jin X, Weekes MP, Plachter B, Sissons JG: The human cytotoxic T-lymphocyte (CTL) response to cytomegalovirus is dominated by structural protein pp65: frequency, specificity, and T-cell receptor usage of pp65-specific CTL. J Virol 1996, 70:7569-7579.

14. Gratama JW, Kern F: Flow cytometric enumeration of antigenspecific T lymphocytes. Cytometry A 2004, 58:79-86.

15. Kern F, Surel IP, Faulhaber N, Frommel C, Schneider-Mergener J, Schonemann C, Reinke P, Volk HD: Target structures of the CD8(+)-T-cell response to human cytomegalovirus: the 72kilodalton major immediate-early protein revisited. I Virol 1999, 73:8179-8184.

16. Slezak SL, Bettinotti M, Selleri S, Adams S, Marincola FM, Stroncek DF: CMV pp65 and IE-I T cell epitopes recognized by healthy subjects. J Transl Med 2007, 5: 17.

17. Gibson L, Piccinini G, Lilleri D, Revello MG, Wang Z, Markel S, Diamond DJ, Luzuriaga K: Human cytomegalovirus proteins pp65 and immediate early protein I are common targets for CD8+ T cell responses in children with congenital or postnatal human cytomegalovirus infection. J Immunol 2004, I 72:2256-2264.

18. Bunde T, Kirchner A, Hoffmeister B, Habedank D, Hetzer R, Cherepnev G, Proesch S, Reinke P, Volk HD, Lehmkuhl H, Kern F: Protection from cytomegalovirus after transplantation is correlated with immediate early I-specific CD8 T cells. J Exp Med 2005, 20I:103I-1036.

19. Khan N, Best D, Bruton R, Nayak L, Rickinson AB, Moss PA: T cell recognition patterns of immunodominant cytomegalovirus antigens in primary and persistent infection. J Immunol 2007, I 78:4455-4465.

20. Sun Q, Burton RL, Dai LJ, Britt WJ, Lucas KG: B lymphoblastoid cell lines as efficient APC to elicit CD8+ $T$ cell responses against a cytomegalovirus antigen. J Immunol 2000, 165:4105-4III.

21. Leen AM, Myers GD, Sili U, Huls MH, Weiss H, Leung KS, Carrum G, Krance RA, Chang CC, Molldrem JJ, Gee AP, Brenner MK, Heslop HE, Rooney CM, Bollard CM: Monoculture-derived T lymphocytes specific for multiple viruses expand and produce clinically relevant effects in immunocompromised individuals. Nat Med 2006, I 2: I I60-I I66.

22. Lucas KG, Sun Q, Burton RL, Tilden A, Vaughan WP, Carabasi M, Salzman D, Ship A: A phase I-II trial to examine the toxicity of CMV- and EBV-specific cytotoxic T lymphocytes when used for prophylaxis against EBV and CMV disease in recipients of CD34-selected/T cell-depleted stem cell transplants. Hum Gene Ther 2000, I I: 1453-1463.

23. Rauser G, Einsele H, Sinzger C, Wernet D, Kuntz G, Assenmacher M, Campbell JD, Topp MS: Rapid generation of combined CMVspecific CD4+ and CD8+ T-cell lines for adoptive transfer into recipients of allogeneic stem cell transplants. Blood 2004, 103:3565-3572.

24. Rowe WP, Hartley JW, Waterman S, Turner HC, Huebner RJ: Cytopathogenic agent resembling human salivary gland virus recovered from tissue cultures of human adenoids. Proc Soc Exp Biol Med 1956, 92:4I 8-424.

25. Provenzano M, Mocellin S, Bettinotti M, Preuss J, Monsurro V, Marincola FM, Stroncek D: Identification of immune dominant cytomegalovirus epitopes using quantitative real-time polymerase chain reactions to measure interferon-gamma production by peptide-stimulated peripheral blood mononuclear cells. J Immunother 2002, 25:342-351.

26. Kern F, Faulhaber N, Frommel C, Khatamzas E, Prosch S, Schonemann C, Kretzschmar I, Volkmer-Engert R, Volk HD, Reinke P: Analysis of CD8 $T$ cell reactivity to cytomegalovirus using protein-spanning pools of overlapping pentadecapeptides. Eur J Immunol 2000, 30: I676-I682.

27. Kuzushima K, Kimura $\mathrm{H}$, Hoshino $\mathrm{Y}$, Yoshimi A, Tsuge I, Horibe K, Morishima T, Tsurumi T, Kojima S: Longitudinal dynamics of Epstein-Barr virus-specific cytotoxic $T$ lymphocytes during posttransplant lymphoproliferative disorder. J Infect Dis 2000 , 182:937-940. 
28. Bao L, Dunham K, Stamer M, Mulieri KM, Lucas KG: Expansion of cytomegalovirus pp65 and IE-I specific cytotoxic $T$ lymphocytes for cytomegalovirus-specific immunotherapy following allogeneic stem cell transplantation. Biol Blood Marrow Transplant 2008, 14:1 I 56-1 I62.

29. Kubo RT, Sette A, Grey HM, Appella E, Sakaguchi K, Zhu NZ, Arnott $D$, Sherman N, Shabanowitz J, Michel H, et al.: Definition of specific peptide motifs for four major HLA-A alleles. J Immunol 1994, 152:3913-3924.

30. Schipper RF, van Els CA, D'Amaro J, Oudshoorn M: Minimal phenotype panels. A method for achieving maximum population coverage with a minimum of HLA antigens. Hum Immunol 1996, $51: 95-98$.

31. Parker KC, Bednarek MA, Coligan JE: Scheme for ranking potential HLA-A2 binding peptides based on independent binding of individual peptide side-chains. J Immunol 1994, I 52:163-175.

32. Rammensee H, Bachmann J, Emmerich NP, Bachor OA, Stevanovic S: SYFPEITHI: database for MHC ligands and peptide motifs. Immunogenetics 1999, 50:213-219.

33. Elkington R, Walker S, Crough T, Menzies M, Tellam J, Bharadwaj M, Khanna R: Ex vivo profiling of CD8+-T-cell responses to human cytomegalovirus reveals broad and multispecific reactivities in healthy virus carriers. J Virol 2003, 77:5226-5240.

Publish with Bio Med Central and every scientist can read your work free of charge

"BioMed Central will be the most significant development for disseminating the results of biomedical research in our lifetime. "

Sir Paul Nurse, Cancer Research UK

Your research papers will be:

- available free of charge to the entire biomedical community

- peer reviewed and published immediately upon acceptance

- cited in PubMed and archived on PubMed Central

- yours - you keep the copyright

Submit your manuscript here:

http://www.biomedcentral.com/info/publishing_adv.asp
BiolMedcentral 